\section{Development and refinement of a portable electronic device for haematocrit determination}

\author{
A.J. Groenewald ${ }^{a \star}$ and H. Pieters ${ }^{b}$
}

A SMALL PORTABLE ELECTRONIC DEVICE named a blood electrometer (BEM), was developed to measure packed cell volume, which can be related to haematocrit (Hct). The electronic circuitry is simple and constructed from standard components. Being battery powered, the device is suitable for bedside or field use ('point-of-care-testing') without specialized training. The effects of temperature, anticoagulants, lipid content, electrode type and different BEM electronic circuits on measurement accuracy were evaluated. A method for calibrating the instrument with a sodium chloride calibrator was also devised and evaluated for measurement accuracy. The response of the BEM to Hct is non-linear; a binomial regression function was used to fit the non-linear response to provide accurate Hct values from $B E M$ readings over a wide range of measurements. The BEM response curve is sensitive to the anticoagulant type used, but specific binomial functions reduce error to between $-3.1 \%$ and $+3.3 \% \mathrm{Hct}$ units. Lipids do not significantly affect BEM readings, even at high concentrations of $9.8 \mathrm{mmol} / \mathrm{l}$. We conclude that the BEM can be relied on for acceptably accurate Hct measurements under a variety of conditions, and can be used for the indirect determination of packed cell volume.

\section{Introduction}

Haematocrit (Hct) is an important parameter in the management of critically ill post-operative patients. ${ }^{1}$ The current opinion and experience is that an Hct of approximately $30 \%$ is optimal for these patients. Although the microcentrifugal (microfuge) method reliably and directly measures packed cell volume (or Hct), it is impractical for 'point-of-care-testing' (POCT) scenarios. ${ }^{2}$ The electroconductivity measurement and microfuge methods have recently been compared when monitoring rehydration in patients with cholera. ${ }^{3}$ There is a need for a robust, self-powered, portable, rapid and reliable POCT method to determine packed cell volume.

Other similar devices have been developed, ${ }^{9-12}$ some being complex. In addition

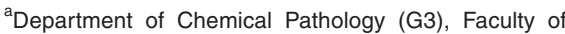
Health Sciences, University of the Free State, P.O. Box 339, Bloemfontein 9300, South Africa.

${ }^{b}$ Department of Haematology (G2), Faculty of Health Sciences, University of the Free State.

*Author for correspondence.

E-mail: gncpajg.md@ufs.ac.za to Hct, they also measure sodium, potassium, chloride, urea and glucose..$^{12}$ Capital and operating costs are unacceptably high for use in primary health care and technical skill is required. Our blood electrometer (BEM), on the other hand, is cheaper, portable and user-friendly. The shortcomings of another similar device were published. ${ }^{9-12}$ Factors including sample temperature, influence of anticoagulants, and the availability of calibration methods, were raised as matters requiring attention.

We describe the construction and operational characteristics of our BEM in terms of sample temperature, different anticoagulants and lipid concentration. The shortcomings mentioned above were addressed in the refinement of the device. A calibrator was also developed to permit field calibration of the instrument.

\section{Materials and methods}

\section{Operation}

Low-frequency alternating current $(\sim 650-700 \mathrm{~Hz})$ flows predominantly through the plasma of the sample, since the cell membranes act as insulators under these conditions. The measured electrical conductance of the sample can therefore be correlated with intercellular plasma void space, and can thus be used to determine Hct.

Each blood sample (minimum $2 \mathrm{ml}$ ) is collected into an evacuated dry 5-ml lithium heparinized (Li-heparin) tube. Duplicate samples are drawn from the same source where required for comparisons of methods. For immediate measurements after venepuncture, the blood is mixed with the anticoagulant by tilting the tube about ten times. The tube is then decapped and inserted in the sample holder of the cell. Alternatively, the heparinized samples are left for $10 \mathrm{~min}$ to reach room temperature before measurements are taken. The BEM cell electrodes are immersed in each sample, and a BEM reading taken, from which the Hct value can be obtained. After successive measurements, the electrodes are cleaned and stored by immersing them in a tube filled with $0.9 \% \mathrm{NaCl}$ solution.

The cell of the BEM consists of a glass tube fitted into a cell holder, which contains a bipolar cardiac pacing lead that serves as an electrode pair (Fig. 1). These sensor electrodes are spaced $1 \mathrm{~cm}$ apart, are not assigned any polarity, as an alternating voltage is applied across them. Current magnitude is related to the sample conductivity. This sample signal is processed by the electronic circuitry to give a nominal reading on a millivoltmeter, these values being used in the determination of Hct.

The electronics and cell of our device resemble those in conductivity equipment commonly used in routine water quality analysis. In both instances, errors from electrode polarization are eliminated by use of an alternating electrical field. Details of the construction and operation of the electronics of our instrument are available in Fig. A online at www.sajs.co.za

\section{Evaluation of BEM components}

Electronic circuits. A test module was made consisting of different resistors of $220,270,330,540$ and $680 \Omega$. The test mod-

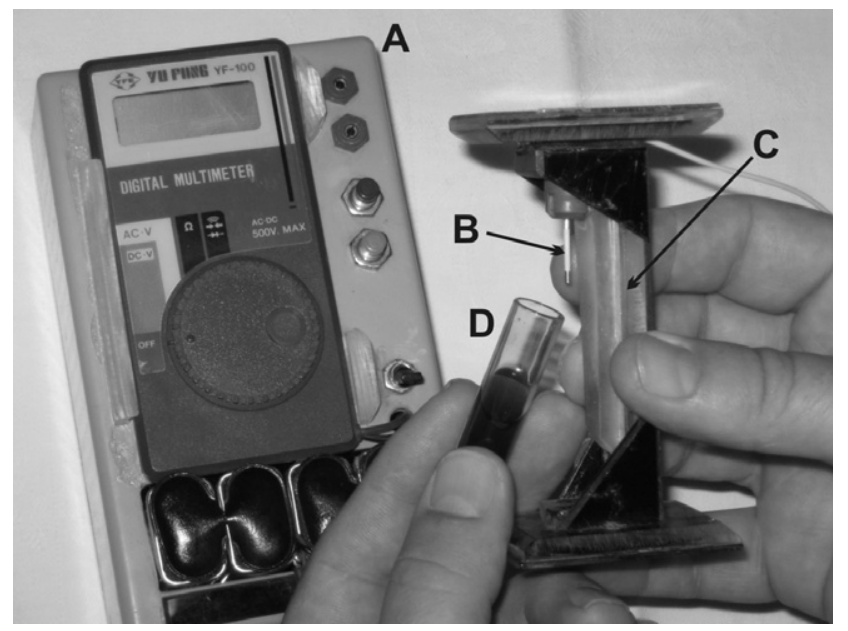

Fig. 1. The blood electrometer (A) with electrode (B), cell holder (C) and glass tube (D). 
ule may be used to pre-calibrate the circuits of different devices. To evaluate the response of different BEMs, four readings for each resistor were taken with five different BEM units prior to pre-calibration.

Electrodes. Four BEM readings for each of four different electrodes were obtained with aqueous $\mathrm{NaCl}$ at concentrations of 6 , $13,19,26,32,38,45$ and $51 \mathrm{mmol} / \mathrm{l}$. The same BEM unit was used with all electrodes, without pre-measurement calibrations.

\section{Evaluation of $\mathrm{NaCl}$ calibrator}

BEM measurements may be influenced by variations in ambient and sample temperature, and each time a new electrode was installed. A $\mathrm{NaCl}$ solution of $49.3 \mathrm{mmol} / \mathrm{l}$ was used as a calibrator solution. Sodium chloride was drawn from a $0.9 \% \mathrm{NaCl}$ solution intravenous infusion bag (SABAX, Johannesburg) and diluted appropriately with distilled water. The $\mathrm{BEM}$ was checked against the $\mathrm{NaCl}$ calibrator solution before each analysis by adjustment of the potentiometer provided for this purpose. A BEM reading of $435 \mathrm{mV}$ at a standard temperature of $21^{\circ} \mathrm{C}$ recorded by the reference circuit (see online information) was used as a reference value. The influence of different electrodes and different temperatures was assessed, taking measurements with three different electrodes on blood at a fixed temperature $\left(21^{\circ} \mathrm{C}\right)$ with widely ranging microfuge Hct values. The same blood sample was also measured at 12, 21 and $29^{\circ} \mathrm{C}$ with the BEM, using the same electrodes and the same $\mathrm{NaCl}$ calibrator at the temperature of the relevant sample.

\section{Effect of other factors on measurement response}

Temperature. The BEM measures conductivity and readings are consequently influenced by sample temperature. Blood electrometer readings were taken after blood samples with microfuge-determined haematocrits of $71,62,52.5,43,35$, 25.5 and $17.5 \%$ Hct units were incubated at temperatures of $20,25,30,35$ and $40^{\circ} \mathrm{C}$, for five minutes. The temperature of one sample in a series was monitored with a thermometer to confirm temperature stability for all samples. A temperature compensation table was compiled from the data. This is needed to allow for any differences in sample temperature should the $\mathrm{NaCl}$ calibrator solution be unavailable.

Anticoagulants. The effect of different anticoagulants such as Li-heparin, EDTA$\mathrm{K} 3$ and K-oxalate/Na-fluoride (commercially available vacuum tubes, VAC-U-
TESTR, Radem Medical, South Africa), ACD-A (Baxter, Toronto, Canada), r-hirudin (Behringwerke, Hoechst, Germany) and Na-citrate (Saarchem, South Africa) on the BEM measurement was evaluated. Where the required formulations were commercially unavailable, $10 \mathrm{ml}$ siliconized glass tubes were filled with the required amount of anticoagulant: $1.5 \mathrm{ml}$ ACD-A, $1 \mathrm{ml}$ of $3.2 \%$ Na-citrate, and $2 \mathrm{mg}$ r-hirudin. In total, $360 \mathrm{ml}$ blood from the same person was used. Although unavoidable, additional liquid may, in the case of ACD-A and Na-citrate, introduce sample dilution with resulting error. Tubes were filled with blood to give a total volume of $10 \mathrm{ml}$, with six tubes per anticoagulant. Red cell and plasma fractions of the various anticoagulants were separated by centrifugation of the samples, removing the supernatant plasma, then pooled red cells, and then the plasma fractions. Red cells and plasma were mixed in ratios that gave ten 5-ml blood samples of each anticoagulant group with microfuge Hct values ranging between zero and $74 \%$ Hct. Microfuge Hct values were compared with BEM-derived Hct values for each anticoagulant group. Blood electrometer Hct values were calculated from experimental measurements using the binomial function, executed by a computer program (Graph Pad Prism, Graph Pad Software, U.S.A.). The binomial function for heparinized blood, as well as the separate functions applied to each anticoagulant group, were used to calculate BEM Hct values. All measurements were performed at room temperature (approximately $24^{\circ} \mathrm{C}$ ) using the same electrode. The BEM was calibrated with the $\mathrm{NaCl}$ reference solution before analysing the sample solutions for each anticoagulant group.

Lipids. Appropriate volumes of a $20 \%$ solution of Intralipid (Fresenius Kabi, South Africa) were added to a plasma pool to mimic varying degrees of lipaemia. The above experiment was repeated on fresh whole blood samples obtained from four volunteers. After separation of the red cell and plasma fractions of the blood sample by centrifuge at $1500 \times g$ for $10 \mathrm{~min}$, Intralipid was added to the plasma fractions. Plasma was then re-combined with the red cells, to give a final Hct value of 47 units. Four BEM readings were made on each sample of the series, per blood donor. Serum triglyceride concentrations were measured for each sample on a Technicon Dax 48 analyser (Bayer-Diagnostics, Johannesburg) to give an index of lipaemia.

Statistical analysis. All data were tested for normal distribution using the ShapiroWilk test. ${ }^{15}$ Paired analysis (95\% confidence intervals for mean difference) was used to measure differences in electrode and circuit response. Least squares linear regression analysis was used to describe the relationship between variables. In some cases, such as the response of the BEM to whole blood, a non-linear least squares binomial regression was used. Confidence interval analyses at $P=0.05$ were used to determine differences between independent means and for paired differences. Accuracy of measurement was calculated as the limits of agreement according to Bland and Altman. ${ }^{16}$

\section{Results and discussion}

All data are available as supplementary online material as tables and graphs at www.sajs.co.za, as follows: Table 1, mean \pm s.d. and $95 \%$ confidence intervals of BEM measurements of different resistors; Table 2 , mean \pm s.d. and $95 \%$ confidence intervals of BEM measurements with different electrodes at different $\mathrm{NaCl}$ concentrations; Table 3, limits of agreement of Hct values measured with different electrodes at different temperatures after calibration with $\mathrm{NaCl}$ calibrator; Table 4, the effect of different anticoagulants on the measurement of Hct; Table 5, paired differences in Hct values (\% Hct) measured by the BEM and microfuge methods; Table 6, effect of lipaemia on BEM measurements. This information is represented graphically in Figs B-F.

\section{Evaluation of BEM components}

Electronic circuits. The mean of four BEM measurements per resistor, and the paired differences between circuit 1 (reference circuit) and the other circuits are given in Table 1. All data, except the BEM measurements between circuits 1 and 5, were normally distributed. The percentage coefficient of variation (CV\%) between the four BEM measurements per resistor was acceptably small $(<0.2 \%)$ for all five circuits. Paired differences between circuits 1 and 3 as well as circuits 1 and 4, however, were statistically significant (95\% CI [13.15; 0.65] and [0.59; -2.79], respectively). The largest difference $(12.5 \mathrm{mV})$ was between circuits 1 and 3 . This equates to $+2.01 \%$ Hct units, calculated for reference Hct. One could compensate for these differences by calibration to the standard BEM circuit. The responses of the BEM circuits were curvilinear.

Electrodes. The mean of four BEM measurements for each electrode pair was directly related to the $\mathrm{NaCl}$ concentration (Fig. C). We calculated the paired differ- 
ences between electrodes 1 and the four other electrodes of BEM measurements at different $\mathrm{NaCl}$ concentrations.

The response of the various electrodes was non-linear and variable. The CV\% between the four BEM per $\mathrm{NaCl}$ concentration was small $(<0.2 \%)$ for all four electrodes. Paired differences between BEM measurements, and between electrodes 1 and the other electrodes, were statistically significant (95\% CI [5.11; -42.11] for electrode 1 versus electrode 2 ; $[-4.55 ;-145.2]$ for electrode 1 versus electrode 3 ; and $[-9.22 ;-56.02]$ for electrode 1 versus electrode 4$)$. The biggest difference (140.7 BEM units) was between electrodes 1 and 3, which equated to $22.7 \%$ Hct units. Data are shown in Table 2.

\section{Evaluation of $\mathrm{NaCl}$ calibrator}

The limits of agreement between the microfuge and BEM Hct measurements at different temperatures after calibration with a standard $\mathrm{NaCl}$ solution are given in Table 3 . Blood Hct values were derived from BEM values by means of a binomial function, fitting microfuge Hct and BEM results, as shown in Fig. B. Figure $C$ shows the differences between actual microcentrifugal Hct values of blood and the Hct values derived from BEM measurements, according to the binomial fit plotted against the mean of derived and microfuged Hct. ${ }^{16}$ It is a scatterplot that gives an indication of the accuracy of BEM-derived Hct readings over a fairly wide range of actual microfuge Hct values. $\mathrm{A} \mathrm{NaCl}$ calibrator was used to compenstae for the influence of variations in sample temperature on BEM Hct measurements. There is no obvious trend of over- or underestimation, and no BEM Hct values differed by more than 1.5 units from microfuge values.

\section{Effect of other factors on measurement response}

Temperature. The BEM readings correlated closely with temperature (Fig. D) (Table 3 online), at each of the different Hct values. Correlation coefficients of $r=$ 0.99 were derived between temperature and BEM readings of blood, with different microfuge Hct values. Linear regression analysis showed that the slope varied between 3.87 and 4.33 BEM units $/{ }^{\circ} \mathrm{C}$, with a mean slope of $3.95 \mathrm{BEM}$ units $/{ }^{\circ} \mathrm{C}$. A mean difference of 3.95 BEM units for every $1^{\circ} \mathrm{C}$ change in temperature was equivalent to $0.82 \%$ Hct units, since a change of $4.97 \mathrm{BEM}$ units translated to $1 \%$ Hct unit for this specific electrode. Thus, a change of more than $3.8^{\circ} \mathrm{C}$ would lead to an error of more than three Hct units.
The slopes of BEM readings of blood with different microfuge Hct values did not differ with temperature change $(F=$ 0.0003).

Anticoagulants. The microfuge Hct values, BEM Hct values derived from the original binomial fit for Li-heparin blood, and the BEM Hct values obtained from separate functions applied to each anticoagulant group, are given in Fig. E and Tables 4 and 5. Figure E shows the differences in response when BEM Hct values were derived from the original binomial fit obtained for Li-heparin. The response difference was especially evident when K-oxalate was used. Although the other anticoagulants (Na-citrate, EDTA-K3, ACD-A) did not appear to have had a major effect on the BEM response to Hct, the accuracy was nevertheless compromised. This was seen in the wide limits of agreement, which varied between -0.3 for 9.8\% Hct and -5.8 for $19.9 \%$ Hct (lower and upper limits). Limits of agreement were small when separate functions for each anticoagulant group had been used to derive BEM Hct.

Although the slopes for r-hirudin and Li-heparin were almost the same, derived Hct values for r-hirudin were almost $4.0 \%$ Hct units higher. The slope of K-oxalate differed the greatest from Li-heparin (Fig. E).

Lipids. Lipids caused an increase in derived Hct values from lipid concentrations of $13.7 \mathrm{mmol} / \mathrm{l}$ and greater. Figure $\mathrm{F}$ (and Table 6 online) shows the relationship between calculated BEM Hct values of plasma/- and blood/Intralipid dilutions. The effect of Intralipid on both plasma/- and blood/Intralipid dilutions was the same when triglyceride concentrations were less than $13.7 \mathrm{mmol} / \mathrm{l}$. The effect on blood/Intralipid dilutions was smaller at higher triglyceride concentrations.

\section{Concluding remarks}

Measurement of haematocrit by the microhaematocrit method in untrained hands in clinics or nursing units carries the risk of inaccuracies, as the line distinguishing the level of packed cells can blur with time and makes interpretation difficult. ${ }^{2}$ Although the electroconductance method has been evaluated to monitor rehydration in Peruvian cholera patients, ${ }^{3}$ this technique is tedious and time-consuming. Treatment with intravenous drips is usual for these patients, and the BEM could be of value to monitor their state of hydration.

The use in the BEM of a commercially available bipolar pacing lead, together with a disposable glass tube as the cell, has certain advantages. These components are easy to replace and pre-calibrate. Distilled water is used to keep the electrode clean. Although relatively large volumes of blood (minimum of $2 \mathrm{ml}$ ) are required to obtain a BEM reading, smaller tubes could be selected for paediatric use. By inserting the electrode into the plunger of a syringe, it should be usable with the BEM as a sterile inline detector to determine packed cell volume during anaesthesia. ${ }^{4}$ The blood can then be re-infused in the patient. Fixed microelectrodes in glass tubes have been described. ${ }^{13,17}$ These components are fragile, expensive and difficult to replace. A special technique is needed to keep such electrodes clean from contamination by fibrin. ${ }^{12}$

In the development and refinement of any instrument for near-patient testing, due consideration must be given to any factors that may influence its accuracy. At the same time, a practical means for calibration must be sought that will sustain accuracy under field or near-patient testing conditions. The main factors that can affect BEM readings have been inherent technical differences in BEM circuitry and electrodes, temperature, the shape of the response curve, the type of anticoagulant used, and the presence of (non-conductive) lipids in the plasma. The need for a control to be used in the field has recently been identified as a primary problem that needs to be addressed in the use of electronic packed cell volume measuring devices. ${ }^{9}$

Virtually no difference was observed between the mean values of different BEM readings obtained using each resistor. In contrast, the response of the different electrodes to various saline concentrations was more variable (Fig. C). The electrodes are identified as likely contributors to variable results from our BEM equipment. All electrodes should be calibrated against the reference Hct method to ensure BEM readings of acceptable accuracy.

BEM readings correlated highly at each of the different Hct values with changes in sample temperature (Fig. D). Changes in temperature did not alter the slope $(F=$ 0.0003) of the BEM response (Fig. D). Temperature compensation will also differ where blood samples have different microfuge Hct values. It is possible to compensate electronically for variations in ambient temperature. ${ }^{9,13}$ This feature was not suitable for our BEM because it would necessitate an impractical time delay between venepuncture and experimental measurement, unless the temper- 
ature probe and electrodes were both in the sample chamber. These additional features will add to the capital costs, placing the equipment out of reach of low-cost point-of-care operators such as clinics. The effect of temperature variation can be effectively controlled by using our $\mathrm{NaCl}$ calibrator.

Small measurement differences were observed between the microfuge and BEM methods when Hct results of the two techniques were compared after calibration with $\mathrm{NaCl}$ at the temperature of the BEM reading (Fig. C). This indicates that the BEM can be effectively calibrated to correct for the various factors affecting its accuracy, namely different electrodes and temperature.

Anticoagulants have an influence on Hct measurements in systems that use conductivity. ${ }^{9,12}$ Our study confirms that different anticoagulants in the blood sample alter the measurement response of our BEM. Our results also show that certain anticoagulants (Na-fluoride/ K-oxalate) can grossly distort the BEM response, to the extent that errors can be as high as $31 \%$ Hct units. Mathematical correction brings the limits of agreement to between $-3.1 \%$ and $3.3 \%$ Hct units, which is within the clinically acceptable error of $5 \%$ units. ${ }^{18}$ We advocate that only one anticoagulant type be used, for reasons of simplicity and practicality (such as EDTA-K3 or Li-heparin) and the appropriate table or plot be used for determining \% Hct values. This reduces the chances of procedure error, especially in field settings. An appropriate table for BEM to Hct conversions can be compiled (for each instrument) at standard room temperature before the equipment is put into service. The underlying reasons for the effects of anticoagulants on the conductivity of blood are not yet clearly understood, despite various explanations having been proposed. ${ }^{19-21}$

A statistically significant change in the BEM reading was observed when the triglyceride concentration in plasma exceeded $9.8 \mathrm{mmol} / \mathrm{l}$ (Fig. F). High lipid concentrations $(<13.7 \mathrm{mmol} / \mathrm{l})$ in blood samples do not influence BEM readings as much as high plasma lipid concentrations (Fig. F). We suggest that it is due to an interactive effect between the membranes of red cells and lipids. The remaining free lipids are insufficient to affect BEM measurements. Blood drawn from a line contaminated by the use of an Intralipid drip may affect BEM readings due to high blood Intralipid concentration.

We conclude that the influence of lipids on BEM readings is negligible, but adaptations are necessary if different anticoagulants are used. We provide a calibrator solution which is easy to use, and allows for accurate BEM measurements under diverse conditions. The BEM equipment is a useful and accurate portable device for the determination of blood Hct in circumstances where standard laboratory instruments are unavailable, or where Hct needs to be continously monitored on a real-time basis. The BEM could thus conceivably be used for POCT. Special training in the use of the BEM is not necessary.

1. Czer L. and Shoemaker W.C. (1978). Optimal haematocrit value in critically ill post-operative patients. Surg. Gynecol. Obstet. 117, 363-368.

2. Kiechle F.L. and Ingram-Main R. (1993). Bedside testing. Beyond glucose. Med. Lab. Obs. 25, 65-68.

3. McDonald J.J., Chanduví B, Velarde G. et al. (1993). Bioimpedance monitoring of rehydration in cholera. Lancet 341, 1049-1051.

4. De Waal A., Hugo J.M., Nel C.J.C. et al. (1989). An electronic apparatus for early detection of changes in red cell content of blood during anaesthesia. S. Afr. Med. J. 76, 148-150.

5. Groenewald A.J., Pieters H. and De Waal A. (1989). Clinical use of a portable electronic device to measure haematocrit. S. Afr. Med. J. 84, 103-105.

6. De Waal A. and Potgieter F.J. (1991). Evaluation of an electronic device used as a quick screening method to detect changes in the red cell content of the blood in horses participating in endurance trail rides. Vet. Res. Commun. 15, 309-314.

7. Groenewald A.J., Pieters H., Coetzee F.F. et al. (1993). Clinical evaluation of an electronic device to measure the haematocrit of athletes during a $64 \mathrm{~km}$ roadrun. South African Journal for Research in Sport, Physical Education and Recreation 17, 41-49.

8. De Waal A., Badenhorst L. and Meyer G.M. (1990). A new apparatus for the measurement of dehydration and overhydration. Comrades Update 3, 14-17.

9. Baris R.R. and Israel A.L. (1988). Clinical evaluation of the Stat-Crit monitor. Proc. Am. Acad. Cardiovasc. Perf. 9, 37-42.

10. Cha K., Faris R.G., Brown E.F. et al. (1994). An electronic method for rapid measurement of haematocrit in blood samples. Physiol. Meas. 15, 129-137.

11. De Vries P.M.J.M., Kouw P.M., Meijer J.H. et al. (1988). Changes in blood parameters during hemodialysis as determined by conductivity measurements. Trans. Am. Soc. Artif. Intern. Organs 34, 623-626.

12. Erickson K.A. and Wilding P. (1993). Evaluation of a novel point-of-care system, the i-Stat portable clinical analyzer. Clin. Chem. 39, 283-287.

13. Kernen J.A., Wurzel H. and Okada R. (1961). New electronic method for measuring haematocrit: clinical evaluation. J. Lab. Clin. Med. 57, 635-641.

14. Wintrobe M.M., Lee G.R., Boggs D.R. et al. (1981) In Clinical Hematology, ed. M.M. Wintrobe, chap. 2, pp. 10-12. Lea and Febiger, Philadelphia.

15. Shapiro S.S. and Wilk M.B. (1965). An analysis of variance test for normality (complete samples). Biometrika 52, 591-611.

16. Bland M.J. and Altman D.G. (1986). Statistical methods for assessing agreement between two methods of clinical measurement. Lancet 1, 307-310.

17. Davis R.E. (1966). An electronic instrument for measuring packed cell volume. Laboratory Practice 15, 1259-1262.

18. Westgard J.O., Seehafer J.J. and Barry P.L. (1994). Allowable imprecision for laboratory tests based on clinical and analytical criteria. Clin. Chem. 40, 1909-1914.

19. Young D.S. and Bermes E.W. (1986). In Textbook of Clinical Chemistry, ed. N.W. Tietz, chap. 3, pp. 478-518. W.B. Saunders, Philadelphia.

20. McCullough J. (1995). In Hematology, ed. E. Beutler et al., chap. 150, pp. 1618-1635. McGraw-Hill, New York.

21. Fiore L. and Detkin D. (1995). In Hematology, ed. E. Beutler et al., chap. 146, pp. 1562-1579. McGrawHill, New York.

This article is accompanied by supplementary figures and tables online at www.sajs.co.za 


\section{Supplementary material to:}

Groenewald A.J. and Pieters H. (2008). Development and refinement of a portable electronic device for haematocrit determination. S. Afr. J. Sci. 104, 457-460.

Table 1. Mean \pm 1 s.d. and $95 \%$ confidence intervals of BEM measurements with different resistors.

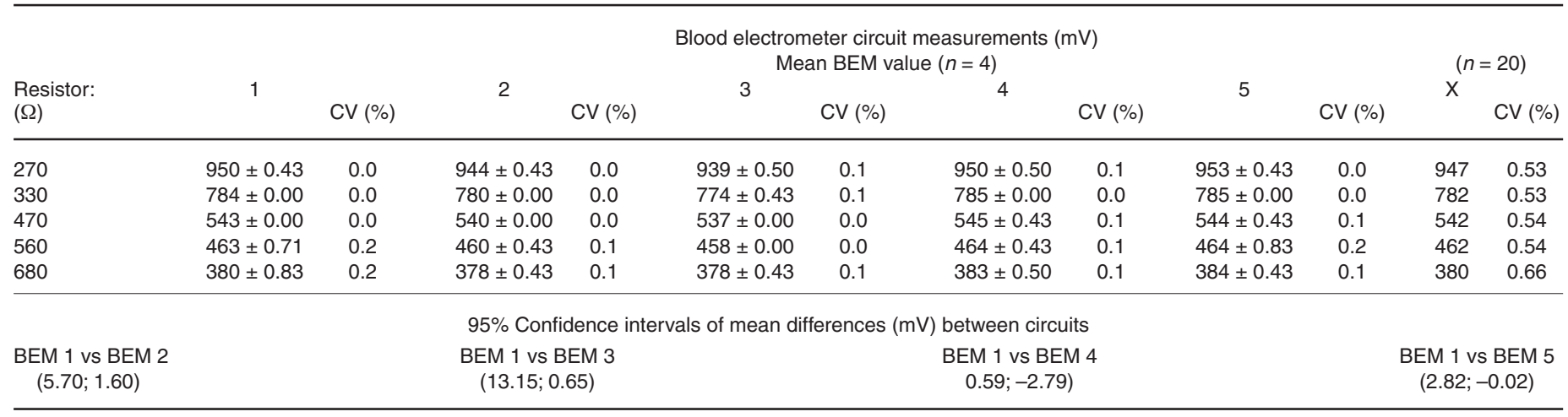

$\mathrm{CV} \%$, Coefficient of variation; s.d., standard deviation

Table 2. Mean \pm 1 s.d. and 95\%-confidence intervals of BEM measurements with different electrodes at different $\mathrm{NaCl}$ concentrations.

\begin{tabular}{|c|c|c|c|c|c|c|c|c|c|c|}
\hline \multirow[b]{2}{*}{$\begin{array}{l}\mathrm{NaCl} \text { conc. } \\
(\mathrm{mmol} / \mathrm{l})\end{array}$} & \multirow[b]{2}{*}{1} & \multirow[b]{2}{*}{ CV (\%) } & \multirow[b]{2}{*}{2} & \multicolumn{3}{|c|}{$\begin{array}{c}\text { Electrodes } \\
\text { Mean BEM value }(\mathrm{mV})(n=4)\end{array}$} & \multirow[b]{2}{*}{4} & \multicolumn{3}{|c|}{$(n=20)$} \\
\hline & & & & CV (\%) & 3 & CV (\%) & & CV (\%) & $x$ & CV (\%) \\
\hline 6 & $167 \pm 0.00$ & 0.0 & $174 \pm 0.00$ & 0.0 & $182 \pm 0.50$ & 0.3 & $178 \pm 0.43$ & 0.2 & 175 & 3.10 \\
\hline 13 & $270 \pm 0.43$ & 0.2 & $292 \pm 0.00$ & 0.0 & $302 \pm 0.00$ & 0.0 & $289 \pm 0.00$ & 0.0 & 288 & 4.05 \\
\hline 19 & $342 \pm 0.83$ & 0.2 & $375 \pm 0.00$ & 0.0 & $401 \pm 0.00$ & 0.0 & $375 \pm 0.50$ & 0.1 & 373 & 5.58 \\
\hline 26 & $406 \pm 0.71$ & 0.2 & $436 \pm 0.00$ & 0.0 & $486 \pm 0.00$ & 0.0 & $435 \pm 0.83$ & 0.2 & 441 & 6.52 \\
\hline 32 & $457 \pm 0.71$ & 0.2 & $486 \pm 0.00$ & 0.0 & $540 \pm 0.00$ & 0.1 & $495 \pm 0.83$ & 0.2 & 494 & 5.99 \\
\hline 38 & $495 \pm 0.83$ & 0.2 & $517 \pm 0.43$ & 0.1 & $594 \pm 0.43$ & 0.1 & $534 \pm 0.71$ & 0.1 & 535 & 6.87 \\
\hline 45 & $538 \pm 0.50$ & 0.1 & $545 \pm 0.43$ & 0.1 & $637 \pm 0.43$ & 0.1 & $576 \pm 0.83$ & 0.1 & 573 & 6.86 \\
\hline 51 & $573 \pm 0.43$ & 0.1 & $571 \pm 0.50$ & 0.1 & $705 \pm 0.00$ & 0.0 & $625 \pm 0.50$ & 0.1 & 618 & 8.83 \\
\hline
\end{tabular}

Electrode 1 vs electrode 2 $(5.11 ;-42.11)$

95\% Confidence intervals of mean differences $(\mathrm{mV})$ between electrodes $(n=5)$

Electrode 1 vs electrode 3 $(-4.55 ;-145.2)$
Electrode 1 vs electrode 4 $(-9.22 ;-56.02)$

$\mathrm{CV} \%$, coefficient of variation; s.d., standard deviation.

Table 3. Limits of agreement of Hct values measured with different electrodes at different temperatures after calibration with $\mathrm{NaCl}$ calibrator.

\begin{tabular}{lcc}
\hline Electrode & Temperature $\left({ }^{\circ} \mathrm{C}\right)$ & Limits of agreement $(\%) \mathrm{Hct})$ \\
\hline Electrode 1 & 21 & $(-1.20 ; 1.78)$ \\
Electrode 2 & 21 & $(-1.40 ; 1.91)$ \\
Electrode 3 & 21 & $(-1.21 ; 1.21)$ \\
Electrode 1 & 12 & $(-1.34 ; 1.24)$ \\
Electrode 1 & 29 & $(-1.33 ; 1.28)$ \\
\hline
\end{tabular}


Table 4. The effect of different anticoagulants on the measurement of haematocrit.

\begin{tabular}{|c|c|c|c|c|c|c|c|c|c|c|c|c|c|c|c|c|c|}
\hline \multirow[b]{3}{*}{ Mic. } & \multicolumn{17}{|c|}{ Haematocrit (\% Hct) } \\
\hline & \multicolumn{3}{|c|}{ Li-Heparin } & \multicolumn{3}{|c|}{$\mathrm{K}-\mathrm{Ox} / \mathrm{NaF}$} & \multicolumn{3}{|c|}{ EDTA-K3 } & \multicolumn{3}{|c|}{ Na-Citrate } & \multicolumn{3}{|c|}{ Hirudin } & \multicolumn{2}{|c|}{ ACD-A } \\
\hline & $\begin{array}{c}\text { BEM } \\
(\mathrm{A})\end{array}$ & $\begin{array}{c}\text { BEM } \\
\text { (B) }\end{array}$ & Mic. & $\begin{array}{c}\text { BEM } \\
(\mathrm{A})\end{array}$ & $\begin{array}{c}\text { BEM } \\
\text { (B) }\end{array}$ & Mic. & $\begin{array}{c}\text { BEM } \\
(A)\end{array}$ & $\begin{array}{c}\text { BEM } \\
\text { (B) }\end{array}$ & Mic. & $\begin{array}{c}\text { BEM } \\
(A)\end{array}$ & $\begin{array}{c}\text { BEM } \\
\text { (B) }\end{array}$ & Mic. & $\begin{array}{c}\text { BEM } \\
(A)\end{array}$ & $\begin{array}{c}\text { BEM } \\
\text { (B) }\end{array}$ & Mic. & $\begin{array}{c}\text { BEM } \\
(\mathrm{A})\end{array}$ & $\begin{array}{c}\text { BEM } \\
\text { (B) }\end{array}$ \\
\hline 0 & 0 & 0 & 0 & -24 & -1 & 0 & -8 & 0 & 0 & -13 & 2 & 0 & 5 & 1 & 0 & -12 & 1 \\
\hline 9.5 & 9 & 9 & 9 & -15 & 9 & 11.5 & 4 & 11 & 12.5 & -2 & 9 & 13 & 16 & 12 & 11 & -1 & 10 \\
\hline 18 & 19 & 19 & 18 & 5 & 20 & 22 & 15 & 22 & 21 & 13 & 21 & 21 & 25 & 21 & 21.5 & 13 & 21 \\
\hline 27 & 27 & 27 & 27 & 2 & 27 & 27 & 21 & 27 & 27.5 & 21 & 28 & 28 & 32 & 27 & 27 & 21 & 27 \\
\hline 34 & 33 & 33 & 32 & 6 & 32 & 32 & 28 & 33 & 33 & 26 & 32 & 33 & 37 & 32 & 32 & 27 & 32 \\
\hline 44 & 44 & 44 & 44 & 16 & 44 & 45 & 41 & 45 & 42 & 41 & 43 & 43 & 47 & 44 & 42 & 39 & 42 \\
\hline 50 & 51 & 51 & 54 & 25 & 53 & 50 & 47 & 51 & 48 & 47 & 49 & 50 & 55 & 52 & 48 & 47 & 49 \\
\hline 60 & 60 & 60 & 64 & 34 & 63 & 60 & 58 & 60 & 56 & 56 & 56 & 60 & 63 & 60 & 58 & 56 & 58 \\
\hline 68 & 67 & 67 & 74 & 44 & 75 & 69 & 68 & 69 & 64 & 65 & 63 & 68 & 71 & 68 & 65 & 64 & 65 \\
\hline
\end{tabular}

Mic., Microfuge method (measured to nearest $0.5 \%$ Hct unit).

BEM(A), Hct value derived from the original binomial fit as for Li-heparin.

BEM(B), Hct values derived from separate fits for each anticoagulant.

Table 5. Paired differences in Hct values (\% Hct) measured by the BEM and microfuge methods.

\begin{tabular}{llccc}
\hline & & Mean difference & s.d. & Limits of agreement \\
\hline \multirow{2}{*}{ Li-Heparin } & Cent-BEM(A) & 0.1 & 0.7 & $-1.4 ; 1.5$ \\
& Cent-BEM(B) & 0.1 & 0.7 & $-1.4 ; 1.5$ \\
\multirow{2}{*}{ K-Ox/NaF } & Cent-BEM(A) & 26.6 & 2.7 & $21.1 ; 32.0$ \\
& Cent-BEM(B) & 0.0 & 1.0 & $-2.0 ; 2.0$ \\
EDTA-K3 & Cent-BEM(A) & 4.7 & 2.5 & $-0.3 ; 9.8$ \\
& Cent-BEM(B) & -0.2 & 0.5 & $-1.2 ; 0.8$ \\
\multirow{5}{*}{ Na-Citrate } & Cent-BEM(A) & 5.6 & 5.7 & $-5.8 ; 16.9$ \\
& Cent-BEM(B) & 0.1 & 1.6 & $-3.1 ; 3.3$ \\
\multirow{4}{*}{ ACD-A } & Cent-BEM(A) & -3.9 & 0.8 & $-5.5 ;-2.3$ \\
& Cent-BEM(B) & -0.1 & 1.1 & $-2.2 ; 2.0$ \\
& Cent-BEM(A) & 5.6 & 5.7 & $-5.8 ; 16.9$ \\
\hline
\end{tabular}

Cent, Microfuge method.

BEM(A), Hct value derived from the original binomial fit as for $\mathrm{Li}$-heparin.

BEM(B), Hct values derived from separate fits for each anticoagulant.

K-Ox, potassium oxalate.

ACD-A, acid citrate dextrose formula A.

Table 6. Effect of lipaemia on BEM measurements.

\begin{tabular}{lcc}
\hline $\begin{array}{l}\text { Lipid concentration } \\
\text { (mmol/l) }\end{array}$ & \multicolumn{2}{c}{ Mean difference \pm s.d. from basal } \\
\cline { 2 - 3 } & Plasma & Blood \\
\hline Basal-6.1 & $0.0 \pm 0.73$ & $0.2 \pm 0.21$ \\
Basal-9.8 & $0.7 \pm 0.73$ & $0.9 \pm 0.39$ \\
Basal-13.7 & $1.3 \pm 0.63^{*}$ & $1.1 \pm 0.43^{*}$ \\
Basal-17.7 & $2.5 \pm 0.44^{*}$ & $1.1 \pm 0.41^{\star}$ \\
Basal-35.4 & - & $2.1 \pm 0.40^{*}$ \\
\hline
\end{tabular}

${ }^{*}$ Difference statistically significant, $P<0.05$. 


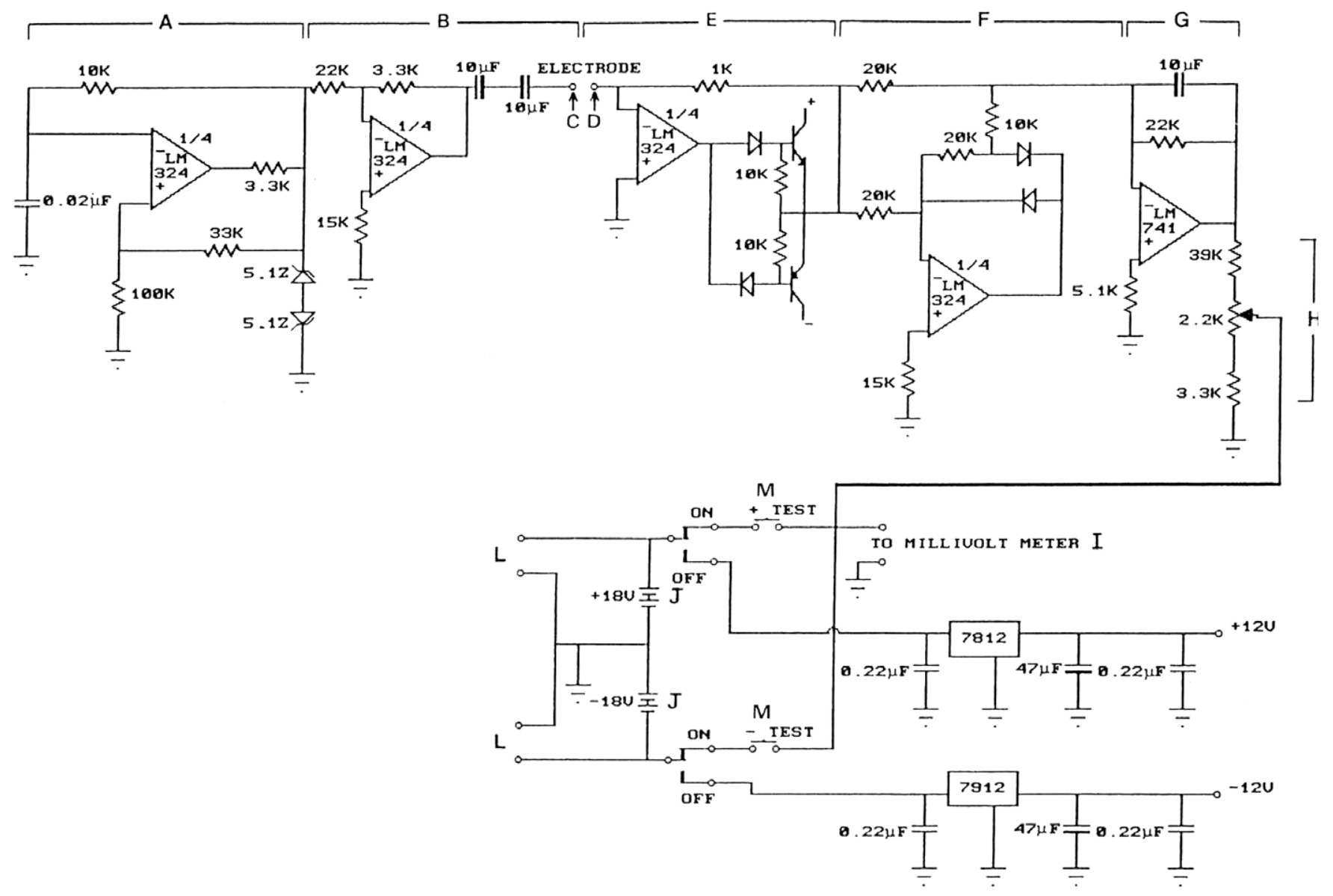

Fig. A. The electronic circuit of the blood electrometer. Units: $\mathrm{K}=\mathrm{k} \Omega, \mu \mathrm{F}=$ microfarad, $\mathrm{V}=\mathrm{volt}, \mathrm{Z}=$ Zenner.

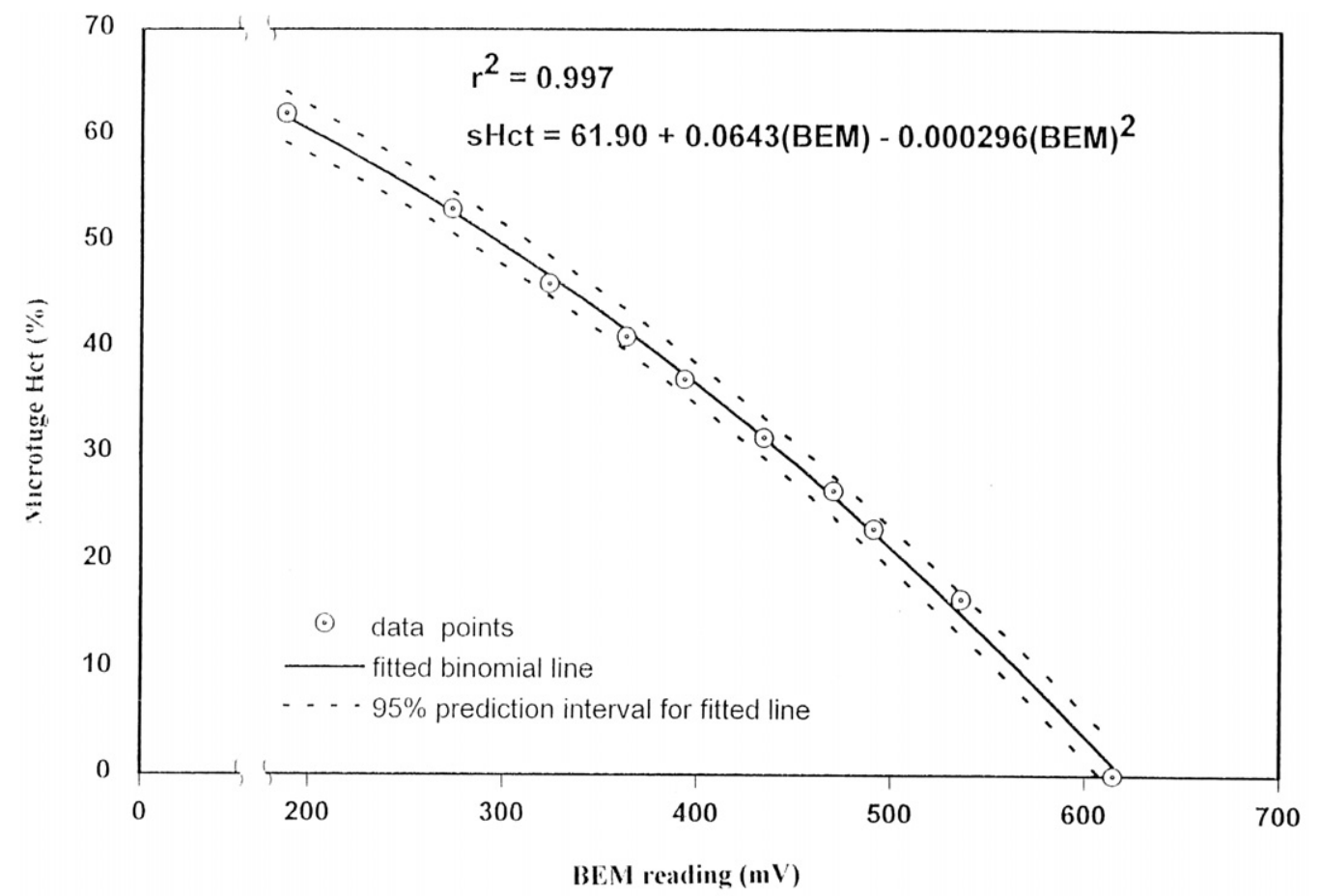

Fig. B. Relationship between BEM reading and haematocrit ( $\mathrm{Hct})$. 


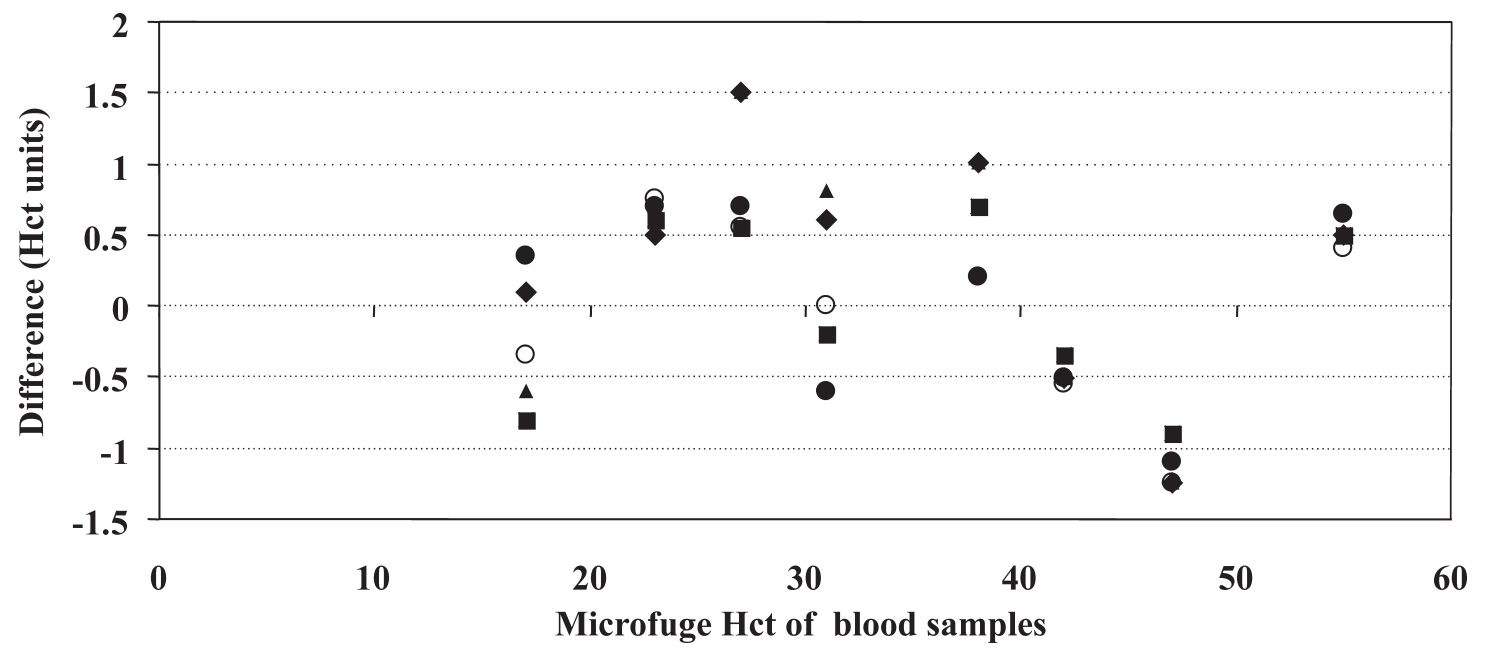

$\rightarrow$ Elect $1\left(21^{\circ} \mathrm{C}\right) \bigcirc \operatorname{Elect} 1\left(12^{\circ} \mathrm{C}\right) \triangle \operatorname{Elect} 2\left(21^{\circ} \mathrm{C}\right) \bullet \operatorname{Elect} 1\left(29^{\circ} \mathrm{C}\right) \square \operatorname{Elect} 3\left(21^{\circ} \mathrm{C}\right)$

Fig. C. Scatterplot giving an indication of the accuracy of BEM-derived Hct readings over a fairly wide range of actual microfuge $\mathrm{Hct}$ values. A NaCl calibrator was used to compensate for the influence of sample temperature on BEM Hct measurements. There is no obvious trend of over- or under-estimation, and no BEM Hct values differed by more that 1.5 units from microfuge Hct values.

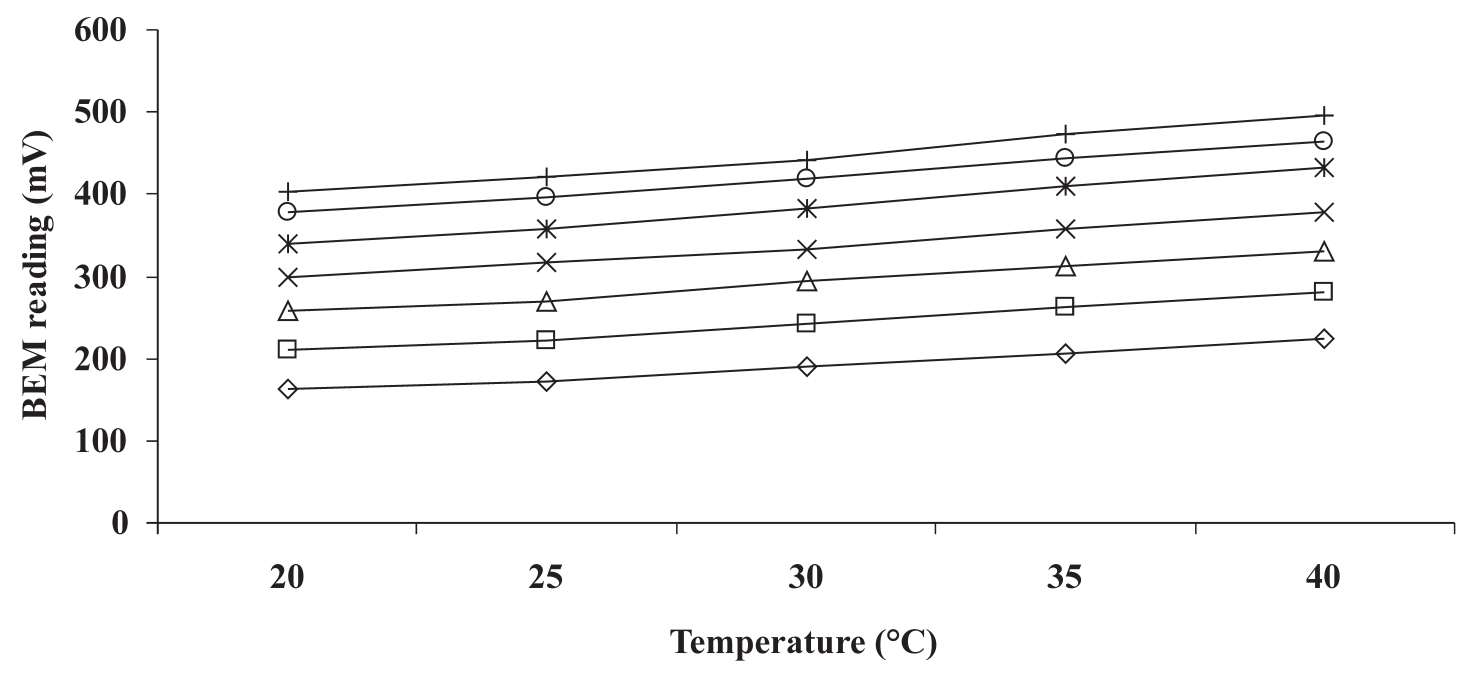

$\diamond$ Het $71 \square$ Het $62 \triangle$ Het $52.5 \rightarrow$ Het $43 \rightarrow$ Het $35-$ Het $25.5 \leftarrow$ Het 17.5

Fig. D. BEM readings of blood with different Hct values at different temperatures. 


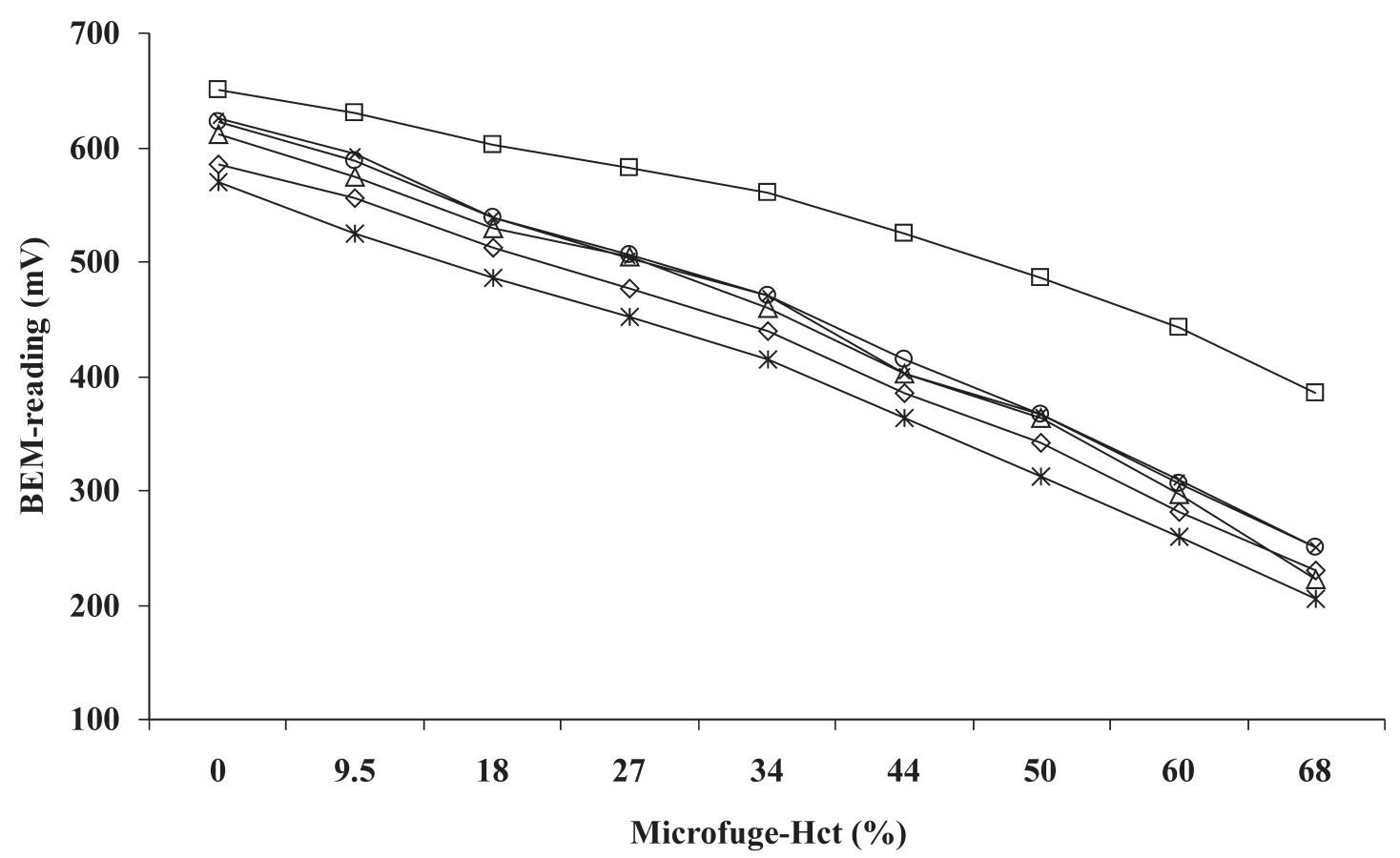

$\diamond$ Li-heparin $\square$ K-oxalate $\triangle$ EDTA-K3 $\rightarrow$ Na-citrate $*$ r-hirudin - ACD-A

Fig. E. Blood electrometer response to different anticoagulants.

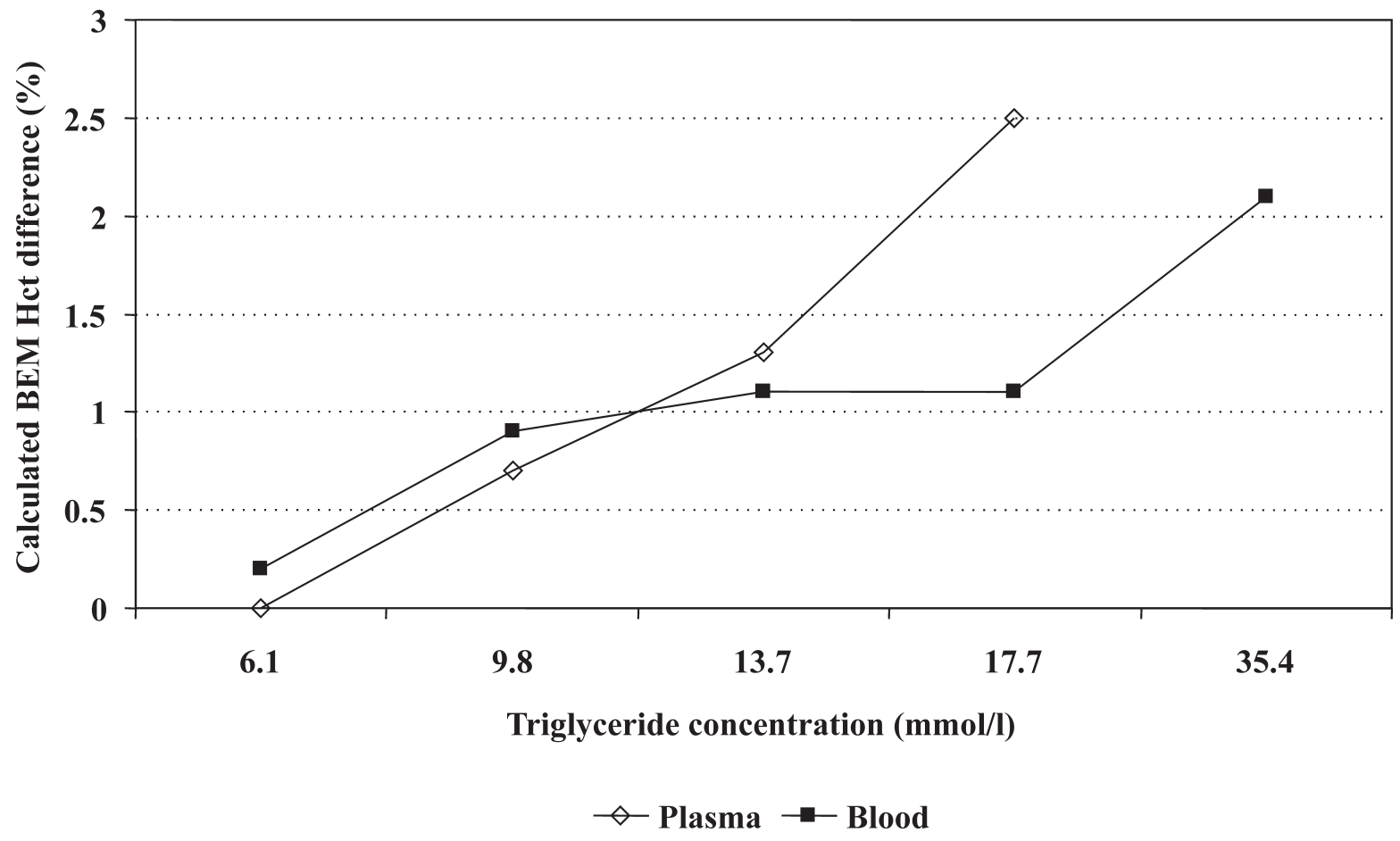

Fig. F. Relationhip between calculated BEM Hct values and triglyceride concentrations. 